the metal, in the process of heating and cooling. This he has shown to be unfounded, by heating steel (previously deprived of all occluded gas) to bright redness in a vacuum tube, and then plunging it in mercury, when it was found to harden just as usual. The same followed when a coil of wire was heated in vacuo by an electric current, to expel the gas, and then quenched in mercury.

The first paper read was by Mr. J. J. Tylor, on meters for registering small flows of water. The many forms of water meter in use are sharply divided into two classes : piston meters, in which the water is made to flow into a cylinder under a piston, and to escape when the cylinder is full, the number of cylinderfuls being measured; and inferential meter:, in which the water is made to turn a fan of some kind, presumably at the same speed as that of the water it elf, and the number of revolutions of this fan is measured. The latter class has often been supposed to be less reliable than the former, especially when the quantity passing is small; but the paper gives the results of several comparative experiments, which show that an inferential meter is at least as accurate as a piston meter for all except the very smallest flows, and that for these neither form is fully to be depended on. In practice, however, it is found that, even in small tenements, little or no water is drawn at so slow a speed as to render meters unreliable. Various tables were given showing the great advantages of the meter as detecting waste, the amount of which, under our present water system, is enormous. Good reason is given for believing that ten gallons per head per day in small houses, and fifteen in large houses, is an ample allowance for the real wants of the population; and yet twenty-seven gal. lons per head is the regular supply of the London water companies. This is probably the most gigantic specimen of organised waste in the world. The means of stopping it are well within the compass of science, and the expense would not be very great; but with the present anarchy in everything connected with metropolitan government, it is, we fear, hopeless to expect the matter to receive attention.

To prevent this waste it is not necessary (as Mr. Tylor pointed out in the discussion) to place a meter in every house. Although many Continental towns are supplied on that system, it would be difficult of introduction in London, and it may be questioned (as various speakers did question) whether it would be worth the expense. The "district meter" system practically accomplishes the same end without this difficulty. On this system a meter is connected with a train of clockwork and drum, so as to register the amount of water passed during successive intervals, say of ten minutes each. The consumption in the different districts of a town, each containing some hundred houses, is measured for 24 hours each, by simply placing the recording meter successively on the mains supplying them. If any of the diagrams thus obtained show special anomalies, the cause can be inquired into: for instance, if a district shows a large quantity of water passing in the small hours of the night, it is obvious that there is serious leakage somewhere; and the inspector proceeds to make a nocturnal tour, and to listen at the stopcocks of each house successively, by which means he can soon detect where the fault lies. In instances given by Mr. Tylor, the use of this simple plan had been effectual in reducing the consumption by fully one-half in particular districts. The system has been applied to the Honses of Parliament; and the consumption of water during some of the prolonged debates of las: session has thus been recorded for the benefit of posterity.

The second paper was by Mr. A. A. Langley (engineer to the Great Eastern Railway), on the system of dredging introduced by M. Bazin, the celebrated hydraulician, on the rivers of France. Nothing can be more simple than this arrangement. An ordinary centrifusal pump is worked on board the dredger, and a flexible pipe leads from the pump to the bottom of the water, where it terminates in an elbow-shaped nozzle. The sand and gravel is sucked up the pipe, passes through the pump, and is conveyed along an open channel to the side of the dredger, where it fall; into a hopper barge or is otherwise disposed of. On this system the water pressure, as will be seen, is used to facilitate the raising of the sand to the surface; whereas in all other dredgers it is a hindrance rather than otherwise. It thus forms an excellent adaptation of scientific principles; and though not applicable fur clay or hard ground, is much cheaper and more rapid than other furms in the removing of sand and shingle. It has also the great advantage that it can be worked in rough water, since a moderate rise and fall of the vessel does not affect the flexible pipe.
There is another point of interest in connection with this dredger. When first started at Lowestoft it was found impos. sible to make it work with anything like speed or economy, owing to the rapid wear of the cheeks and blades of the pump, which were cut by the sand exactly as glass is cut in the sandblast process. After many trials the evil was stopped by the simple process of protecting the blades of the fan by pieces of thick india-rubber, which from its softness and elasticity yields to the cutting action, and thus escapes much injury itself, while it prevents all injury to the cheeks. This peculiar property of india-rubber has, we believe, been previously utilised in connection with the sand-blast process, but it has never been adopted on so large a scale, and it certainly deserves to be very widely known.

In the course of the discussion Mr. Charles Ball, who has worked a large number of these dredgers, mentioned that he had forced sand thus dredged for a distance of 600 yards through horizontal pipes, by the mere action of the pump. To prevent the silt from settling during its passage along open troughs, he had inserted a light ${ }^{*}$ angle iron in an undulating line along the inside of the trough, so as to give the water a continual twisting motion as it travelled onwards. The great difficulty was to prevent the water from ceasing to flow, either from the sand accumulating above the pump, or from old sacks and other rubbish choking the nozzle. The former was got over mainly by making the discharge-pipe horizontal, and giving it a siphon bend, which kept the water always within it, and prevented any difficulty in starting the pump; and the latter by making openings in the nozzle, just above the grating, which were covered by an indiarubber band having slits in it. When the grating got choked and a vacuum began to form inside the nozzle, these slits opened to the pressure, and allowed the water to flow in.

The third paper was by Mr. E. B. Ellington, on hydraulic lifts for passengers and goods. The risks which attend the use of ordinary chain lifts were minutely described, and also the way in which these are removed by the use of direct acting hydraulic lifts, in which the cage rests on the top of a column of pressurewater, both in ascending and descending. The chief difficulty with such lifts is to balance the dead weight of the cage and attachments, so as to save the needless expenditure of power in raising these each time; and an ingenious arrangement of hydraulic cylinders is described, by which this is attained without the use of counter-weights or chains. A table of experiments on lifts of this and other types is given, which shows the efficiency to be very high, ranging from 75 to 80 per cent. The discussion on this paper was adjourned, for want of time, to the next meeting.

\section{THE CHEMISTRY OF BAST FIBRE ${ }^{1}$}

I $\mathrm{N}$ a previous paper isee Chem. News, 43, 77, and Chem. Soc. Four. xxxviii. 666) the authors established the following points :-The chemical similarity between the non-cellulose constituents of monocotyledonous and dicotyledonous fibres; the reiolution of the jute fibre by chlorine into cellulose (using this word in a general sense), and the chloroderivative of an aromatic body, $n\left\{\mathrm{C}_{19} \mathrm{H}_{18} \mathrm{Cl}_{4} \mathrm{O}_{9}\right\}$; all bast fibres examined (flax, hemp, manilla, esparto, \&c.) yielded a similar body; the reactions of this substance suggested the hypothesis that it was a complicated derivative of tetrachlorquinone; jute fibre was resolved by boiling dilute hydrochloric or sulphuric acid into 2 . soluble carbohydrate and an insoluble compound of the aromatic body with the more stable form of the cellulose ; dilute nitric acid resolves the fibre into cellulose and a nitroderivative of the aromatic constituents $n\left\{\mathrm{C}_{25} \mathrm{H}_{31}\left(\mathrm{NO}_{2}\right) \mathrm{O}_{23} \mathrm{H}_{8}\right\}$; no constituent of the nature of pectose was found. From these facts the authors drew the conclusion that jute fibre consists of cellulose intimately associated with a complicated body allied to the yuinones, in fact, a cellulide after the type of the glucosides, the aromatic body being united to cellulose in place of glucose. They also observed that the chlorinated body, when treated with a solution of sodium sulphite, develops a magnificent purple colour; this reaction was applied for the detection of bast fibres. In the present paper the authors have continued this line of research. To the aromatic constituent of the jute fibre the authors assign the formula. $\mathrm{C}_{19} \mathrm{H}_{22} \mathrm{O}_{9}$. The resemblance of this formula to that of catechin, $\mathrm{C}_{19} \mathrm{H}_{18} \mathrm{O}_{8}, 3 \mathrm{H}_{2} \mathrm{O}$, suggested a comparative investigation of the latter substance; both catechin and catechu.

${ }^{x}$ Abstract of papers by C. F. Cross and E. J. Bevan at the Chemieal Society, January 19. 
tannic acid yielded a chlorine derivative resembling that mentioned above, which gave a brilliant magenta colour with sodium sulphite. Moreover, from a specimen of jute fibre which had become rotten through shipment in a damp state, a body was extracted having all the properties of a tannin. Esparto resin, when fused with potash, furnished phloroglucin and much protocatechuic acid. The general identity of these non-cellulose constituents with the class of astringent substances or tannins is thus fully established.

The authors then give details as to the bromine and chlorine compounds obtained from Esparto resin; they next investigate the action of caustic alkalies on the chlorine derivative $\mathrm{C}_{19} \mathrm{H}_{18} \mathrm{Cl}_{4} \mathrm{O}_{9}$ of jute-fibre, by which action two atoms of chlorine were removed, as is the case with chloranil. By the action of bromine on jute-fibre a brominated compound was obtained similar to that from Esparto resin. As regards the constitution of these derivatives the authors are inclined to believe that their molecule is built up round chloranil as a centre. Chloranil, when boiled with sugar, forms a brown substance which behaves with alkalies and chlorine exactly like the aromatic substance obtained from bast fibres.

The authors next consider the wider problem of the relation of the cellulose to the non-cellulose constituents of bast-fibres and the relation of both to the life of the plant. In these points they have been anticipated by the investigations and inferences of the physiological botanists Sachs, Sachsse, \&c., who have stated that cellulose is directly derived from starch or its physical equivalents sugar, fat, or inulin, and is not a product of the resolution of a proteid molecule; this formation of cellulose is attended with the evolution of carbonic anhydride. The chemical changes are expressed by Sachsse thus :-

$$
\mathrm{n}\left(\mathrm{C}_{36} \mathrm{H}_{60} \mathrm{O}_{30}+{ }_{30} \mathrm{O}\right)=\mathrm{n}\left({ }_{30} \mathrm{CO}_{2}+{ }_{24} \mathrm{H}_{2} \mathrm{O}+\mathrm{C}_{6} \mathrm{H}_{12} \mathrm{O}_{6}\right) \text {; }
$$

the molecule $\mathrm{nC}_{6} \mathrm{H}_{12} \mathrm{O}_{6}$ is then transformed into substances having the atomic ratio $\mathrm{C}_{6} \mathrm{H}_{10} \mathrm{O}_{5}$. The formation of cellulose usually occurs in tho:e portions containing no chlorophyll; the formation of starch, on the other hand, is associated with tha presencc of chlorophyll and the evolution of oxygen. The lignification of fibres originally consisting of pure cellulose is held by Sachs to be a modification of the cell-substance (cellulose), and not an infiltration of substances from the contents of the cell. This change is expressed by Sachsse thus :-

$$
\mathrm{C}_{\text {Ci4 }} \mathrm{H}_{40} \mathrm{O}_{20}=5 \mathrm{H}_{2} \mathrm{O}+\underset{\text { Lignin }}{\mathrm{C}_{18} \mathrm{H}_{24} \mathrm{C}_{16}}+\mathrm{C}_{6} \mathrm{H}_{6} \mathrm{O}_{5} \text {. }
$$

Sachsse thinks that it is to this more highly oxidised molecule $\mathrm{C}_{6} \mathrm{H}_{6} \mathrm{O}_{5}$ that the origin of the tannins is to be referred. The authors dissent from this equation, and think that bodies resembling metapectic acid $\mathrm{C}_{8} \mathrm{H}_{14} \mathrm{O}_{9}$ are formed. Such bodies have been found by Kolbs in linen-fibre, and by the authors in the portions of the jute-fibre near the roots (jute-cuttings). Sachs maintains that the tannins are degradation products of cellulose and are to be looked upon as excreta, like urea in the animal. If now the extreme terms of the developmental series are the cellulose and the tannins, it devolves upon the chemist to investigate the intermediate stages of the transformation. The authors therefore treated jute fibre with dilute (5 per cent.) sulphuric acid at moderate temperatures; as a result of these experiments they conclude that the jute fibre consists for the most part not of cellulose, but of a transition form between the original carbohydrate and its ultimate modification of a soluble astringent. To this transitional modification the authors give the name of bastose, as the authors consider there are many celluloses, so also there will be many forms of bastose. The aromatic derivatives derived from these bastoses the authors propose to call bastins. The authors then adduce various argaments to prove that the conversion of carbo-hydrates into aromatic bodies is possible. Thus Hoppe Seyler, by heating starch to high temperatures with water, formed pyrocatechin. Gun cottons or nitrocelluloses degrade spontaneously into bodies of the pectic class, and the authors, by the action of strong sulphuric acid on dextrin at 7 per cent., obtained a black substance which furnished a chlorinated product resembling in its properties the chlorobastin previously described. The formation of the black substance was accompanied with that of acetic and carbonic acids. The authors conclude the paper with the results of several miscellaneous researches bearing on the subject. The stony concretions of pears can be converted into cellulose, and a chlorobastin giving the colour reaction with sodic sulphite. The origin of tannins, the reactions of jute substance under high pressure, the reduction of indigo by jute, the reaction of linseed oil with sulphuric acid, and additional observations on the chlorobastins, are the titles of these miscellaneous researches. The authors finally embody their results in a diagrammatic survey or genealogical tree : Carbonic anhydride and water, by the action of light, protoplasm and chlorophyll, form starch; starch and oxygen during the growth of the plant give off $\mathrm{CO}_{2}$ and $\mathrm{H}_{2} \mathrm{O}$, pectin and cellulose being formed. The starch passes through bastose to bastin. Bastose can be split up in various ways by chlorine into cellulose and chlorobastin, by dilute sulphuric acid into furfurol, acetic acid, \&c., and tannins (insoluble) by decay into pectic acid, and tannins (soluble) by nitric acid into cellulose and a nitro body. Bastin, by fusion with $\mathrm{KHO}$, furnishes phloroglucin and protocatechuic acid, and by chlorination carbonic acid and chlorobastin.

\section{NOTES FROM THE OTAGO UNIVERSITY MUSEUM}

\section{I.-On a New Method of Preserving Cartilaginous Skeletons and other Soft Animal Structures}

$\mathrm{N}$ reading Professor Miall's account of the employment of glycerine jelly for the preservation of anatomical prepara. tions (NATURE, vol. xviii. p. 312), it occurred to me that many of the more solid and less complicated structures, usually kept in spirit, might possibly be preserved by thoroughly impregnating them with glycerine jelly and then allowing them to dry. I was able to make very few experiments in this direction before leaving England, but during the present year I have tested the method I am about to describe enough to make me feel tolerably confident in recommending it as of especial value for cartilaginous and partially ossified skeletons, and useful also for such things as hearts, stomachs, and other viscera, and for the exoskeletons of Crustacea, Echinoderms, \&c.

I will first describe the method adopted in preparing the skeleton of a fresh Elasmobranch. The fish is eviscerated, the gills removed and placed in strong spirit, and the body plunged into water a few degrees below the boiling point. An immersion varying from a few seconds to a few minutes serves to soften the mucle and connective tissue to such an extent that they can readily be stripped from the cartilage without injury to the latter. This I find the only satisfactory way of cleansing many parts of the elasmobranch skeleton, notably the vertebral column. In the case of the gills even a momentary immersion in hot watex is liable to cause a separation of the cartilages; they are therefore best prepared in the cold, after theligaments have been well hardened with alcohol. After the remainder of the skeleton is cleansed it may either be put through the preserving process at once, or previously hardened in alcohol-the latter alternative is the best, since it diminishes subsequent shrinking, but it is not essential and may very well be dispensed with in the case of large skeletons, for the sake of saving the otherwise large expenditure of alcohol. I need hardly say that it is always advisable to separate the skull from the vertebral column, the pectoral fin from the shoulder girdle, \&c., as in this partially disarticulated condition the skeleton is more easily manipulated, besides being more convenient for future use. In the case of large sharks it is also necessary to divide the vertebral column into pieces small enough for the vessel used in the preserving process.

The various parts of the skeleton, with or without previous hardening in alcohol, are then placed in "glycerine fluid " of the following composition :-

$$
\begin{aligned}
& \begin{array}{llllll}
\text { Glycerine } & \ldots & \ldots & \ldots & \ldots & \text { I litre }
\end{array}
\end{aligned}
$$

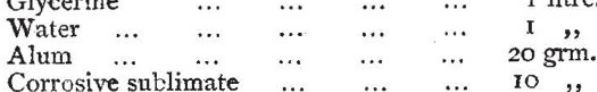

This fluid is a modification of Wickersheimer's, the chief alteration being the omission of alcohol: the alum may also be omitted if the specimen has been hardened with alcohol. After remaining in the fluid until thoroughly permeated-two days to a week, according to size-the skeleton is transferred to the following glycerine jelly :-

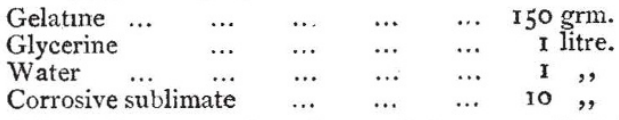

The jelly is kept at a heat just sufficient to melt it, in an earthenware vessel (neither the glycerine fluid nor the jelly should be allowed to come in contact with metal), over a water 